\title{
Reproductive experience influences grooming behavior during pregnancy in rats
}

A.P. Serafim and L.F. Felicio
Departamento de Patologia, Faculdade de M edicina Veterinária e Zootecnia, Universidade de São Paulo, São Paulo, SP, Brasil

\section{Correspondence \\ L.F. Felicio \\ Departamento de Patologia \\ Faculdade de Medicina Veterinária \\ Universidade de São Paulo \\ Av. O rlando Marques Paiva, 87 \\ 05508-900 São Paulo, SP \\ Brasil \\ Fax: +55-11-3818-7829 \\ E-mail: Ifelicio@ usp.br}

Research supported by FAPESP (No. 96/4193-0) and CNPq (No. 520234/ 96) to L.F. Felicio. A.P. Serafin was the recipient of fellowships from FAPESP and CNPq.

Received June 5, 2001

Accepted January 22, 2002

\section{Abstract}

The pregnancy-induced increase in self-licking observed in rats is important for mammary gland development and lactation. Reproductive experience has epidemiologial implications such as a decrease in the incidence of mammary gland cancer in women and it also influences various behavioral, neurochemical and endocrine parameters. The aim of the present study was to investigate the influence of reproductive experience on grooming behavior patterns during pregnancy in rats. Self-grooming behavior was measured in age-matched virgin, primi- and multigravid (days 7, 8, 9, 19, and 20 of pregnancy) rats. General grooming (head, forelimbs and shoulders) was not significantly different among virgin, primi- and multigravid rats during pregnancy. Confirming previous work, pregnant rats spent significantly more time in specific grooming (mammary glands, nipple lines, genital and pelvic regions) than did virgin animals. In addition, selflicking of mammary glands was significantly increased in multi- as compared to primigravid rats on days $8,9,19$ and 20 of pregnancy. The increase in mammary gland grooming observed in multigravid rats appears to be a consequence of previous reproductive experience. These data show that reproductive experience modulates mammary gland grooming during pregnancy, possibly contributing to successful reproduction.

In adult female mammals a reproductive experience, i.e., mating, pregnancy, parturition and lactation, has long-term behavioral, endocrine and neurochemical implications (1-6). These influences have been demonstrated in various physiological states (7). Particularly during pregnancy, a previous reproductive experience induces changes in both endocrine and neurochemical profile $(8,9)$. Diurnal and nocturnal prolactin surges are less intense in multigravid than in primigravid female rats (8). Before the diurnal
Key words

- Self-licking

- Parity

- Lactation

- Mammary gland

- Prolactin

- Dopamine prolactin surge, dopamine levels in striatal and hypothalamic homogenates are higher and the haloperidol-induced increase of central dopamine metabolites is lower in multigravid than in primigravid rats (9). Grooming behavior is under the influence of the endocrine milieu (10). Various neurotransmitters can modulate the expression of this behavior as well (11). During pregnancy female rats change their grooming patterns, tending to lick their mammary glands more than prior to pregnancy $(12,13)$. This in turn 
Figure 1. Duration of self-grooming of the head, forelimbs and shoulders in non-pregnant, and primigravid and multigravid females according to the day of pregnancy. Nulli $=$ nulliparous. has been shown to be important for mammary gland development and lactation (14). We hypothesized that a previous reproductive experience would influence the expression of grooming during pregnancy in rats. To test this hypothesis grooming patterns of virgin, primi- and multigravid rats were compared in age-matched female rats.

Adult virgin female Wistar rats from our colony weighing 180-220 g were housed individually in polypropylene cages ( $45 \times 25$ x $20 \mathrm{~cm}$ ) under a controlled light-dark cycle (lights on from 6:00 to 18:00 h) at a temperature of $22 \pm 3^{\circ} \mathrm{C}$. Water and food were available ad libitum. Rats were randomly assigned to one of three groups. Initially, one set of rats was mated. After mating, pregnant females were again housed individually and allowed to give birth. Their neonates were culled to six pups the day after parturition, and these dams raised their litters to weaning on day 21 postpartum. Approximately 2-3 weeks after pup weaning from the first set of animals, both the reproductively experienced and part of the inexperienced females were time-mated to our colony males, thereby generating three age-matched groups of rats,

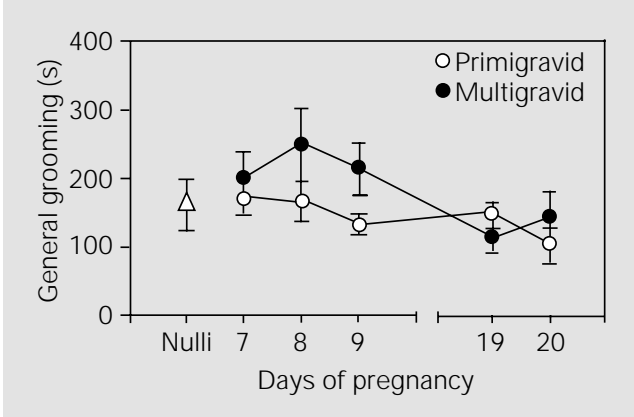

Figure 2. Duration of self-grooming of the mammary glands, nipple lines, genital and pelvic regions in non-pregnant, and primigravid and multigravid females according to the day of pregnancy. $* P<0.05$ compared to primigravid rats (ANOVA followed by the Duncan test). Nulli $=$ nulliparous. a multigravid one (second pregnancy), a primigravid one (first pregnancy) and a group of virgin animals. The day sperm was observed in the vaginal lavage of each female was designated day 1 of pregnancy. Animals used in this study were maintained in accordance with the guidelines of the Committee on Care and Use of Laboratory Animal Resources, National Research Council, USA.

Grooming behavior was videotaped during 30-min test sessions on days 7, 8, 9, 19 and 20 of pregnancy. Virgin animals were observed on every testing day as well. To minimize possible circadian influences, observations of animals from different groups were intermixed; observations began at 8:00 am and animals were placed in the same order every day. Each rat was videotaped under room light in her own cage with a glass cover. Two habituation sessions were held on days preceding the day of the first testing session. Self-licking was recorded according to the body region to which it was confined. Head, forepaws, shoulders and upper back were recorded as general grooming, while nipple lines, genital and pelvic regions were considered as mammary gland and anogenital grooming. The duration in seconds of each of these behavioral categories was recorded during individual 30-min sessions.

Two-way repeated measures analysis of variance (ANOVA) followed by the Duncan test was used to compare grooming behavioral data. A probability of $\mathrm{P}<0.05$ was considered significant for all comparisons.

Time spent in general grooming was not significantly different among virgin, primigravid and multigravid rats on any observation day (Figure 1). Statistical analysis showed a significant main effect of group on grooming of mammary glands. As can be seen in Figure 2, pregnant rats spent more time grooming the mammary glands than virgin females on days 7, 8 and 19 of pregnancy $(\mathrm{P}<0.05)$. On days 8, 9, 19 and 20 of pregnancy multigravid animals spent sig- 
nificantly more time in specific (mammaryanogenital) grooming than primigravid rats $(\mathrm{F}=16.1, \mathrm{P}<0.05)$ (Figure 2).

The present results show that reproductive experience modulates the behavioral grooming patterns displayed during pregnancy in rats. Particularly, time spent in selflicking of the mammary glands and genital regions increases during the second pregnancy as compared to the same behavior displayed by age-matched primigravid rats. Previous findings demonstrated that reproductive experience modulates a series of physiological and pharmacological responses (2-4,7-9). Other studies have indicated that multiparous female rats are also less sensitive to the opioid regulation of maternal behavior $(2-4,15)$ and analgesia (2) than are primiparous females. Higher doses of opiates are needed to obtain a drug-induced disruption of maternal behavior in experienced animals. Both basal and drug-induced increases of plasma prolactin levels are lower in cycling parous than in age-matched virgin rats $(7,8)$. Similarly, both opioid-induced release and suckling-stimulated prolactin release are less intense in multiparous than in primiparous rats (4). Since self-licking of the mammary glands is important for good lactation, the increase in time spent in self- grooming of these glands may compensate for the parity-induced decrease in plasma prolactin levels. This study does not inform about the peripheral feedback effects on mammary gland function as a whole. However, since mammary gland grooming is necessary for good lactation, its modulation by reproductive experience might be part of a physiological process that leads to the optimization of the whole reproductive phenomenon.

We have previously observed that both ex vivo and in vivo increases in striatal dopamine metabolites HVA and DOPAC concentrations after haloperidol treatment were less intense in primiparous than in nulliparous rats and less intense in multigravid than in primigravid animals $(9,16)$. Dopaminemediated behaviors are also modulated by reproductive experience $(17,18)$. Since dopaminergic systems play a role in grooming behavior $(19,20)$ and dopaminergic function is modulated by this same experience $(9,18)$, the reproductive experience-induced increase in pregnant rat self-licking described here may be related to changes in dopaminergic function. The present results may reflect reproductive experience-induced changes in processes involving neurotransmission and/ or neuromodulation.

\section{References}

1. Del los Monteros AE (1991). Differential PRL response to oral metoclopramide in nulliparous versus multiparous women throughout the menstrual cycle. Fertility and Sterility, 55: 885-889.

2. Kinsley $\mathrm{CH} \&$ Bridges RS (1988). Parityassociated reductions in behavioral sensitivity to opiates. Biology of Reproduction, 39: 270-278.

3. Mann PE \& Bridges RS (1992). Neural and endocrine sensitivities to opioids decline as a function of multiparity in the rat. Brain Research, 580: 241-248.

4. Mann PE, Kinsley $\mathrm{CH}$, Ronshein $\mathrm{PM} \&$ Bridges RS (1989). Long-term effects of parity on opioid and nonopioid behavioral and endocrine responses. Pharmacology,
Biochemistry, and Behavior, 34: 83-88.

5. Musey VC, Collins DC, Brogan DR, Santos VR, Musey PI, Martino-Saltzman D \& Preedy J RK (1986). Long-term effects of the first pregnancy on the hormonal environment: Estrogens and androgens. J ournal of Clinical Endocrinology and Metabolism, 64: 111-118.

6. Musey VC, Collins DC, Musey PI, MartinoSaltzman D \& Preedy J RK (1987). Longterm effect of a first pregnancy on the secretion of prolactin. New England J ournal of Medicine, 316: 229-234.

7. Bridges RS, Henriquez BM, Sturgis J D \& Mann PE (1997). Reproductive experience reduces haloperidol-induced prolactin secretion in female rats. Neuroendocrinol- ogy, 66: 321-326

8. Bridges RS, Felicio LF, Pellerin LJ , Stuer AM \& Mann PE (1993). Prior parity reduces post-coital diurnal and nocturnal prolactin surges in rats. Life Sciences, 53: 439-445.

9. Felicio LF, Florio J C, Sider LH, CruzCasallas PE \& Bridges RS (1996). Reproductive experience increases striatal and hypothalamic dopamine levels in pregnant rats. Brain Research Bulletin, 40: 253-256.

10. Cools AR, Spruijt BM \& Ellenbroek BA (1988). Role of central dopamine in ACTHinduced grooming behavior in rats. In: Colbern DL \& Gispen WH (Editors), Neural Mechanisms and Biological Significance of Grooming Behavior. Annals of the New 
York Academy of Sciences, 525: 338-350.

11. Serafim AP \& Felicio LF (2001). Dopaminergic modulation of grooming behavior in virgin and pregnant rats. Brazilian J ournal of Medical and Biological Research, 34: 1465-1470.

12. Roth LL \& Rosenblatt J S (1966). Mammary glands of pregnant rats: development stimulated by licking. Science, 151: 1403-1404.

13. Roth LL \& Rosenblatt J S (1967). Changes in self-licking during pregnancy in the rat. J ournal of Comparative and Physiological Psychology, 63: 397-400.

14. Roth LL \& RosenblattJ S (1968). Self-licking and mammary development during pregnancy in the rat. J ournal of Endocrinology, 42: 363-378.

15. Bridges RS \& Hammer RP (1992). Parityassociated alterations of medial preoptic opiate receptors in female rats. Brain Research, 578: 269-274.

16. Hucke EETS, Cruz-Casallas PE, Florio J C $\&$ Felicio LF (1998). Reproductive experience reduces striatal dopaminergic responses in freely moving female rats. NeuroReport, 9: 3589-3593.

17. Byrnes EM \& Bridges RS (2001). Parity potentiates the effects of apomorphine on sensomonitor gating and stereotypy. Pharmacology, Biochemistry, and Behavior, 68: 481-489.
18. Hucke EETS, Cruz-Casallas PE, Sider LS \& Felicio LF (2001). Reproductive experience modulation of dopamine-related behavioral responses. Pharmacology, Biochemistry, and Behavior, 68: 575-582.

19. Cromwell HC \& Berridge KC (1996). Implementation of action sequences by a neostriatal site: a lesion mapping study of grooming syntax. J ournal of Neuroscience, 16: 3444-3458.

20. Drago F, Contarino A \& Busa L (1999). The expression of neuropeptide-induced excessive grooming behavior in dopamine D1 and D2 receptor-deficient mice. European J ournal of Pharmacology, 365: 125131. 